\title{
Psychological and sex features of delayed gut transit in functional gastrointestinal disorders
}

\author{
E J Bennett, P Evans, A M Scott, C-A Badcock, B Shuter, R Höschl, C C Tennant,
} J E Kellow

\begin{abstract}
Background-The relation of demographic and psychological factors to the presence and extent of gut transit impairment in the functional gastrointestinal disorders has received little attention. Aims-To compare the psychosocial and demographic features of patients with functional gastrointestinal disorders and delayed transit in one region of the gastrointestinal tract with those displaying more widespread delayed transit (that is, delay in two or three regions), and those with normal transit in all three regions.

Patients-Of 110 outpatient participants who satisfied standardised criteria for functional gastrointestinal disorders, 46 had delayed transit in one region, 32 had delay in two or three regions, and 17 exhibited normal transit in all regions.

Methods-Transit in the stomach, the small intestine, and the large intestine was assessed concurrently using a wholly scintigraphic technique; psychological status was assessed using established psychometric measures.

Results-Patients with delayed transit displayed demographic and psychological features that contrasted with patients with normal transit in all regions. In particular, widespread delayed transit featured female sex, a highly depressed mood state, increased age, frequent control of anger, and more severe gastric stasis, while the features distinguishing normal transit were male sex and high levels of hypochondriasis.

Conclusion-These data suggest the existence of a distinct psychophysiological subgroup, defined by the presence of delayed transit, in patients with functional gastrointestinal disorders.

(Gut 2000;46:83-87)
\end{abstract}

Keywords: delayed gut transit; psychophysiology; sex; mood

Medicine

C C Tennant

Department of

Nuclear Medicine

B Shuter

R Höschl

Correspondence to:

Dr J E Kellow, Department of Medicine, University of Sydney, Royal North Shore Hospital, St Leonards NSW 2065, Australia.

Accepted for publication 21 July 1999

A range of psychological factors, such as tional distress, hypochondriasis, and an inadequate coping style, have been associated with the functional gastrointestinal disorders (FGID) ${ }^{1-4}$ Female sex, ${ }^{5}$ a depressed mood state, ${ }^{67}$ anxiety, ${ }^{8}$ and the control and suppression of anger, ${ }^{9}$ have also been linked to inhibition of gut contractile activity in patients with these disorders. However, although impaired (delayed) gut transit is present in some patients with FGID, the demographic and psychologi- cal features of this pathophysiological condition remain poorly defined; in particular, whether more extensive disturbances in transit are associated with a greater degree of psychological distress than more localised disturbances is not known. Furthermore, the relation of impaired transit to type and number of coexistent FGID has received little attention.

Our first aim therefore, was to determine and compare, among patients with FGID, the demographic and psychological predictors of: (1) delayed gastrointestinal transit (in one region of the digestive tract, namely the stomach, the small intestine, or the large intestine); (2) widespread delayed transit (delay in two or three regions); and (3) normal transit in all three regions. Our second aim was to determine the relation of FGID syndromes to the extent of impaired transit. We employed a novel wholly scintigraphic technique for assessing transit, enabling assessment of all three regions of the gut concurrently.

\section{Methods}

PATIENTS

One hundred and ten consecutive outpatients (91 women, mean age 44 (15) years) with FGID were studied; FGID included irritable bowel syndrome (IBS), functional constipation (FC), unspecified functional bowel disorder, and functional dyspepsia (FD) syndromes (dysmotility-like, ulcer-like, reflux-like, and unspecified functional dyspepsia). All patients fulfilled the criteria for these FGID as elaborated by Drossman, ${ }^{10}$ and organic disease had been excluded by appropriate diagnostic studies. All drugs known to affect gastrointestinal motility, including laxatives, were ceased at least 24 hours prior to scintigraphy. Premenopausal women were studied in the follicular phase of the menstrual cycle. Approval for the procedures was given by the Medical Research Ethics and Radiation Safety Committees of the Royal North Shore Hospital, and all subjects gave informed consent.

ASSESSMENT OF GASTROINTESTINAL TRANSIT Gastric emptying and small intestinal transit Evaluation of gastric emptying was carried out as described previously. ${ }^{11}$ At 900 am on day 1 , after an overnight fast, subjects consumed a
Abbreviations used in this paper: DT1, delayed transit in one region only; DT2, delayed transit in two or more regions; FC, functional constipation; FD, functional dyspepsia; FGID, functional gastrointestinal disorder; IBS, irritable bowel syndrome; NT, normal transit in all three regions; ROI, region of interest; $t_{1 / 2}$, half emptying time. 
standard meal (1.78 MJ; protein $14 \%$, carbohydrate $27 \%$, fat $58 \%$ ); the solid phase was labelled with $20 \mathrm{MBq}$ technetium-99m sulphur colloid, and the liquid phase with $4 \mathrm{MBq}$ indium-111 DTPA. ${ }^{11}$ For the assessment of small bowel transit, images were acquired at 15 minute intervals between one and four hours. A stomach region of interest (ROI) was used after realignment of the gastric emptying data, while caecal ROI or markers on the patient were used to reregister the small bowel data. In order to compensate for potential attenuation of counts as the meal traversed the end of the small bowel and arrived in the caecum and proximal colon, a normalising ROI including the caecum and all small bowel/gastric activity was used to define total activity for small bowel transit. Solid time-activity curves were generated by subtraction from the ${ }^{99 \mathrm{~m}} \mathrm{Tc}$ curves of the product of down scatter fraction and ${ }^{111} \mathrm{In}$ curves. Attenuation corrected solid and liquid curves were generated from geometric means of anterior and posterior images, corrected for decay, and a power exponential function fitted. For gastric emptying, solid and liquid half emptying time $\left(\mathrm{t}_{1 / 2}\right)$ and solid lag time (time to $2 \%$ emptying) were calculated. Similar parameters of filling were generated for the small bowel curves. Small intestinal transit time for solid and liquid phases was calculated as the time from $50 \%$ gastric emptying to $50 \%$ caecal filling. ${ }^{12} 13$

\section{Colonic transit}

Anterior and posterior 10 minute images of the abdomen and pelvis were obtained at $6,24,48$, 72 , and 96 hours, with the subject in a supine position. ${ }^{14}$ In order to obtain information which was as physiological as possible, subjects resumed their normal diet and activities following the six hour acquisition. Decay corrected time-activity points were obtained from geometric means of ${ }^{111}$ In counts (maximum colon activity taken as $100 \%$ ), and joined with a linear point to point fit. The resultant curve was used to derive the time to $50 \%$ colon emptying.

Scintigraphic data were compared with those obtained in 58 healthy asymptomatic subjects (43 women, mean age 39 (11) years). The sex composition of the patient and control groups was similar. For each region, abnormality was defined as one or more scintigraphic parameters outside the 5 th to 95 th percentiles of the control data for each sex with respect to delay and with respect to acceleration in transit. Four healthy females were outside the 5 th to 95 th percentiles for gastric emptying, and one for small bowel transit for the female group; no male control fell outside the control range for males. The accuracy of the scintigraphic method has been documented recently. ${ }^{1516}$

PSYCHOSOCIAL ASSESSMENT

Psychometric measures assessed included demographic factors (age, sex, and marital, educational, and occupational status), and psychological variables including emotional distress/mood state, personality, coping style, and emotional expression/suppression.

\section{Emo tional distress/mood state}

Depression - assessed by the Centre of Epidemiological Studies Depression Scale. ${ }^{17}$

State anxiety-items measure current levels of tension and apprehension (Spielberger State and Trait Anxiety Inventory (Form Y). ${ }^{18}$

\section{Personality}

Neuroticism - high scores reflect a tendency to over emotionality, and excessive worry.

Extroversion - to assess orientation to things external or internal (Eysenck Personality Inventory). ${ }^{19}$

Trait anxiety - to assess the tendency to anxious states (Form Y). ${ }^{18}$

Trait anger - anger temperament (the disposition to express anger), and anger reactivity (responses based on evaluations of situations as negative; Spielberger's State-Trait Anger Scale).$^{20}$

General hypochondriasis - the tendency to be inappropriately concerned about one's health (nine item subscale of Illness Behaviour Questionnaire). ${ }^{21}$

Coping style

The tendency to use immature, neurotic, and/or mature defences (the Defence Style Questionnaire). ${ }^{22}$

Emotional expression/suppression

(1) To reflect the degree of suppression of unwanted emotions - anger, anxiety, and depression (Courtauld Emotional Control Scale). ${ }^{23}$ (2) Anger in, anger out, anger control (Anger Expression (AX) Scale). ${ }^{24}$

DATA AND STATISTICAL ANALYSES

Patients were subdivided into three groups according to the presence or absence of delayed transit in each region: patients with delay in one region (DT1, $\mathrm{n}=46$ ); patients with delay in two or more regions (DT2, n=32); or patients in whom all regions displayed normal transit (NT, n=17). Fifteen patients with accelerated transit were excluded because they had accelerated transit coexisting with delayed or normal transit. Age and sex distributions in transit subgroups were compared by analysis of variance for age, and the $\chi^{2}$ test for sex. Analysis of variance was also used to assess differences with respect to scores on the hypochondriasis and depression scales. Stepwise multiple logistic regression analyses were performed to determine the psychological and demographic features, and in separate analyses, the FGID subgroup features, of the DT1 and DT2 subgroups, in contrast to patients with NT, and in comparison with each other. FGID predictor variables included: type of syndrome, combinations of FD syndromes with IBS and FC, and total number of syndromes present. Mann-Whitney $U$ and Wilcoxon signed rank tests were performed to compare the severity of stasis in each gut region (stomach, small bowel, colon) of patients in the DT1 and DT2 groups. All probability values were two tailed with alpha set at 0.05 . 
Table 1 Parameters of gastrointestinal transit in the healthy control group $(n=58)$

\begin{tabular}{lccc}
\hline & Median & 5th centile & 95th centile \\
\hline Stomach & & & \\
$\quad$ Solid $\mathrm{t}_{1 / 2}$ & 103 & 6.4 & 156 \\
$\quad$ Solid lag & 13 & 4 & 27 \\
$\quad$ Liquid $\mathrm{t}_{1 / 2}$ & 37 & 13 & 66 \\
Small bowel & & & \\
$\quad$ Solid $\mathrm{t}_{1 / 2}$ & 78 & 36 & 153 \\
$\quad$ Liquid $_{1 / 2}$ & 69 & 27 & 153 \\
Colon $_{1 / 2}$ & 38 & 18 & 73 \\
\hline
\end{tabular}

\section{Results}

GASTROINTESTINAL TRANSIT

Of the 46 patients in the DT1 group, 16 (35\%) displayed delay in the stomach, $10(22 \%)$ in the small bowel, and $20(43 \%)$ in the colon. The corresponding proportions for the 29 patients in the DT2 group (11 (34\%), seven $(21 \%)$, and $14(45 \%)$, respectively) were similar $(\mathrm{p}<0.05)$.

Table 1 shows summary transit parameters for each region in the healthy control group. Table 2 shows the median (and centile) values for delayed transit (solid $\mathrm{t}_{1 / 2}$ ) times according to the subgroups of DT1 and DT2. Gastric stasis was significantly increased in patients with multiple regions of delayed transit (DT2); the severity of small bowel and colonic stasis did not differ between groups.

Table 2 The severity of delayed transit in each gut region for patients with delayed transit in one region (DT1) and in multiple regions (DT2)

\begin{tabular}{|c|c|c|c|c|c|c|}
\hline & \multicolumn{3}{|l|}{$D T 1$} & \multicolumn{3}{|l|}{$D T 2$} \\
\hline & $\begin{array}{l}25 \text { th } \\
\text { centile }\end{array}$ & $\begin{array}{l}\text { 50th } \\
\text { centile }\end{array}$ & $\begin{array}{l}75 \text { th } \\
\text { centile }\end{array}$ & $\begin{array}{l}\text { 25th } \\
\text { centile }\end{array}$ & $\begin{array}{l}\text { 50th } \\
\text { centile }\end{array}$ & $\begin{array}{l}\text { 75th } \\
\text { centile }\end{array}$ \\
\hline Stomach` & 163.9 & 170.1 & 200.1 & 164.1 & 231.1 & 253.3 \\
\hline Small bowel & 161.8 & 255.6 & 381.2 & 170.8 & 206.4 & 371.4 \\
\hline Colon & 86.4 & 94.3 & 95.1 & 82.5 & 93.6 & 95.3 \\
\hline
\end{tabular}

$\mathrm{t}_{1 / 2}$ times/values are shown (solid, for the stomach and small bowel)

${ }^{\star}$ DT2 $>$ DT1 $($ p $<0.05)$.

Table 3 Summary of differences in age, sex, depression, and hypochondriasis between transit subgroups

\begin{tabular}{|c|c|c|c|}
\hline & $N T$ & $D T 1$ & $D T 2$ \\
\hline Age (y); mean (SD) & $38(17)$ & $42(13)$ & $49(14)^{\star}$ \\
\hline Female:male ratio & $1.8: 1$ & $6.8: 1+$ & $9.7: 1+$ \\
\hline Depression scores; mean $(\mathrm{SE}) \ddagger$ & $13(2.6)$ & $11(1.2)$ & $16(3.2)^{\star}$ \\
\hline Hypochondriasis scores; mean (SE)』 & $2.6(0.5)$ & $1.4(0.2) \dagger$ & $1.4(0.3) \dagger$ \\
\hline
\end{tabular}

${ }^{*} \mathrm{p}<0.05$ versus $\mathrm{NT}$ and $\mathrm{DT} 1 ; \dagger \mathrm{p}<0.05$ versus NT.

Normative data

$\ddagger$ The cut off score for depression of probable clinical significance is $\geqslant 17 .{ }^{25}$

\The mean (SD) hypochondriasis scores are $1.44(1.8)$ for general practice patients, and 2.69 (2.3) for psychiatric patients. ${ }^{21}$

NT, normal transit; DT1, delayed transit in one region; DT2, delayed transit in multiple regions.

Table 4 Frequency of functional gastrointestinal disorders (FGID) for each gut transit subgroup

\begin{tabular}{llllll}
\hline Transit subgroup & $\begin{array}{l}\text { IBS } \\
n(\%)\end{array}$ & $\begin{array}{l}F D^{*} \\
n(\%)\end{array}$ & $\begin{array}{l}\text { UFBD } \\
n(\%)\end{array}$ & $\begin{array}{l}\text { UFD } \\
n(\%)\end{array}$ & $\begin{array}{l}F C \\
n(\%)\end{array}$ \\
\hline NT $(\mathrm{n}=17)$ & $13(76)$ & $2(12)$ & 0 & 0 & $2(12)$ \\
DT1 $(\mathrm{n}=46)$ & $36(78)$ & $4(9)$ & $1(2)$ & $2(4)$ & $3(7)$ \\
DT2 $(\mathrm{n}=32) \ddagger$ & $23(72)$ & $4(12.5)$ & $3(9)$ & 0 & $4(13)$ \\
\hline
\end{tabular}

^Functional dyspepsia (FD) subgroups: dysmotility-like, ulcer-like, and reflux-like dyspepsia. †Unspecified functional bowel disorder (UFBD) and unspecified functional dyspepsia (UFD) occurred alone.

$\ddagger$ Row total exceeds 32 as two patients with functional constipation (FC) also had FD.

Note: no FGID subgroup, combination of subgroups, or total number of subgroups was significantly associated with gut transit status.

IBS, irritable bowel syndrome; NT, normal transit; DT1, delayed transit in one region; DT2, delayed transit in multiple regions.
DEMOGRAPHIC FACTORS

Table 3 summarises group differences in age and sex. The age of patients in the DT2 subgroup was significantly higher than in the DT1 or the NT subgroups; age did not differ, however, between the DT1 and the NT subgroups. With respect to sex, the female:male ratio was significantly greater in both subgroups with delayed transit. Sex was most discriminating of delayed versus normal transit for patients with delayed transit in two or more regions; the probability of being a female was almost eight to one for patients in this group (odds ratio $=7.6 ; 95 \%$ confidence interval $=$ $1.44 ; \mathrm{p}=0.02)$. There were no differences between transit subgroups with respect to marital, educational, or occupational status (data not shown).

PSYCHOLOGICAL AND DEMOGRAPHIC FACTORS In comparison with normal transit, depression scores were significantly higher in the subgroup of patients with widespread delay in transit (DT2; table 3). In contrast, hypochondriasis scores were significantly lower in both delayed transit (DT1, DT2) subgroups (table 2). Normative data (table 3) for depression ${ }^{25}$ and general hypochondriasis ${ }^{21}$ show that mean depression scores are indeed high in the widespread delayed transit group (DT2), as are hypochondriasis scores in the NT group.

The psychological profile of widespread delayed transit (DT2) comprised increased depression, together with low levels of hypochondriasis (variance explained $=41.5 \%$ ). A post hoc analysis revealed that for those patients with three regions delayed these same variables (depression and hypochondriasis) together with anger control strongly predicted delayed transit in all three regions (variance explained $=84 \%$ ). In a separate analysis, female sex and increasing age together predicted DT2 relative to NT (variance explained $=45 \%$ ).

The psychological profile of normal transit, after controlling for the effects of depression, included both male sex and high levels of hypochondriasis.

FGID FACTORS

Table 4 summarises the frequency of FGID syndromes for each transit subgroup. No FGID variable in the regression model (type of syndrome, combination of syndromes, or the number of syndromes present) predicted transit subgroup (NT, DT1, DT2).

\section{Discussion}

The main finding of the current study was that in patients with FGID, the presence or absence of delayed gut transit, particularly widespread (multiple regions of) delayed transit, was associated with contrasting demographic and psychological features. The prominent feature of both groups of patients with delayed transit was female sex and low levels of hypochondriasis; both of these features, together with depression and age, increasingly discriminated delayed from normal transit as the number of regions displaying delay increased. For patients with three regions delayed, psychological 
factors alone (low levels of hypochondriasis and high levels of depression and anger control) explained most (84\%) of the variance in gut stasis. The predictors of delayed transit did not include any particular type of FGID syndrome, any combination of syndromes, or the total number of syndromes present. Rather, these data support the existence of a discrete psychophysiological subset within the FGID (those with a specific type of impaired transit) that seems to be independent of symptom based subgroups. An important clinical dimension of widespread delayed transit is the increased severity of gastric stasis in patients within the DT2 group; this strong relation between the severity of gastric stasis and the extent (number of regions) of gut stasis, previously unreported, is consistent with the observations of delayed gastric emptying in response to experimental rectal distension. ${ }^{26}$

Although this is the first study to link female sex to widespread impaired transit, the relation itself is not without earlier reference; whole gut transit time tends to be slower in women generally $^{27}{ }^{28}$ and women are more prevalent than men among patients with gastric ${ }^{529-31}$ and colonic motor dysfunctions, ${ }^{82}$ at least in western cultures. ${ }^{33}$ Few women and no men in the healthy control sample in this study had abnormal transit. It seems therefore that the strong association of female sex to delayed transit, especially widespread delayed transit, in these FGID patients is not simply a reflection of a more global sex bias. Indeed, the increased strength of the relation of female sex to widespread impaired transit (relative to the whole sample, to DT1 and NT) in this study, may help to explain the disproportionate representativeness of women in patient groups with FGID, in those with constipation, ${ }^{8}$ and especially in those with severe and refractory FGID. It also runs counter to the notion that their referral for gastrointestinal investigation was provoked by illness concerns that were inappropriate; this likelihood is further supported by their very low scores on the general hypochondriasis scale.

The strength and nature of the relation of a depressed mood state to slow transit has not been fully explored. A significant association has been reported in patients with functional gastrointestinal symptoms and predominant depression, ${ }^{7}$ but not in psychiatric outpatients with a diagnosis of major depression (with and without symptoms compatible with a diagnosis of IBS).$^{34}$ Only one study suggests that the relation of whole gut transit times to degree of depression (from questionnaire responses) may be quantitative. ${ }^{34}$ Our findings support the specificity of the association (depression, but not anxiety, with delayed transit), and expand and qualify quantitative aspects of this relation. The association is sensitive to increases in the number of regions displaying delayed transit (perhaps also to type of region), occurs more often in women, is accompanied by a restrained coping style that resists inappropriate illness concerns (general hypochondriasis), and attempts to control and suppress anger; the relation is independent of type of FGID, personal- ity, and other aspects of coping. These results are consistent with our earlier finding of a strong positive relation between the frequency of anger suppression and the extent of gastric stasis, a relation that was enhanced in the presence of an overtly sad and depressed state. ${ }^{9}$ The similarity of the psychological ${ }^{9}$ and $\operatorname{sex}^{5}$ features of the severity of gastric stasis to those of widespread delayed transit supports the correspondence found in this study between the severity of gastric stasis and the extent (number of regions) of delayed gut function.

The association of depression and controlled anger with gut stasis identifies a distinct and recognisable psychophysiological subset of patients with FGID. The association is consistent with the view that gut motor function alters in accordance with the ongoing function of the whole individual. ${ }^{35}$ While a contrasting psychophysiology (increased emotional and gastrointestinal expressiveness) that is distinctive for men is suggested by reports of extraversion in healthy male subjects with faster transit, ${ }^{36}$ current evidence suggests that for men a homogeneous psychophysiology is unlikely. Male sex, which was so strongly associated with normal transit in this study of FGID patients, has been associated also with faster transit in healthy individuals. ${ }^{27}{ }^{28} \mathrm{~A}$ less clearly defined psychophysiology for men with FGID might be expected, however, given other reported sex differences such as the greater likelihood for IBS symptoms to match the Rome criteria for women than for men. ${ }^{37}$

With the exception of sex, the predictors of normal transit seem to explain more about influences on health care seeking and referral than about influences on gastrointestinal transit per se. Based on the higher prevalence of somatic concerns in patient groups with FGID in comparison with non-patient groups, ${ }^{38}$ it has been proposed that the primary precipitant of health care seeking, and hence of patient status in FGID, is an enhanced perception of the severity of symptoms and their potential seriousness (represented in this study by scores on the general hypochondriasis scale). Certainly, abnormal illness attitudes ${ }^{38} 39$ and generalised illness concerns ${ }^{4}$ (independent of depression) have been associated specifically with outpatient IBS relative to organic gastrointestinal disease, ${ }^{39}$ and to other FGID (for example, FD, FC) subgroups. ${ }^{4}$ This study suggests, however, that health care seeking based on an increased somatic focus is not widespread, and when present, it is associated with a specific combination of factors.

In summary, these findings identify an important subset of FGID patients distinguished by a distinct psychophysiology that is most complete for patients with widespread delayed transit; specific features include female sex, more severe gastric stasis, a highly depressed mood state, the control of anger, and increasing age. Part of this work was published in abstract form in Gastroenter-
ology (1996;110:A632). This work was supported by a Project Grant from the National Health and Medical Research Council of Australia. The support of Lady Eileen Proud is also gratefully of Australia. The
acknowledged. 
1 Creed F. Relationship of non-organic abdominal pain to psychiatric disorder and life stress. In: Creed F, Mayo R, Hopkins A, eds. Medical symptoms not explained by organic
disease. London: Royal Colleges of Psychiatrists and Physidisease. London: R

2 Whitehead WE. Psychosocial aspects of functional gastrointestinal disorders. Gastroenterol Clin North Am 1996;25 $21-34$

3 Farthing MJG. Irritable bowel, irritable body, or irritable brain? BMF 1995:310:171-5.

4 Bennett EJ, Piesse C, Palmer $\mathrm{K}$, et al. Functional gastrointestinal disorders: psychological, social and somatic features. Gut 1998;42:414-20.

5 Stanghellini V, Tosetti C, Paternicò A, et al. Risk indicators of delayed gastric emptying of solids in patients with functional dyspepsia. Gastroenterology 1996;110:1036-42.

6 Almy TP. Experimental studies on the irritable colon. Am F Med 1951;9:60-7.

7 Chaudhary HR. Study of intestinal transit time in patients with anxiety and depression. F Assoc Physicians India 1989; with anxiety

8 Devroede G, Girard G, Bouchoucha M, et al. Idiopathic constipation by colonic dysfunction: relationship with per:1428-33.

9 Bennett EJ, Kellow JE, Cowan H, et al. Suppression of anger and gastric emptying in patients with functional dyspepsia. Scand $\mathcal{F}$ Gastroenterol 1991;27:869-74.

10 Drossman DA. The functional gastrointestinal disorders: diagnosis, pathophysiology, and treatment. Boston: Little, Brown \& Co., 1994

11 Scott AM, Kellow JE, Shuter B, et al. Effects of cigarette smoking on solid and liquid intragastric distribution and gastric emptying. Gastroenterology 1993;104:410-16.

12 Neilsen OH, Gjørup T, Christensen FN. Gastric emptying rate and small bowel transit time in patients with irritable bowel syndrome determined with $99 \mathrm{mT}$ c-labeled pellets and scintigraphy. Dig Dis Sci 1986;31:1287-91.

13 Camilleri M, Colemont LJ, Phillips SF, et al. Human gastric emptying and colonic filling of solids characterized by a new method. Am ₹ Physiol 1989;257:G284-90.

14 Smart RC, McLean RG, Gaston-Parry D, et al. Comparison of oral iodine-131-cellulose and indium-111-DTPA as tracers for colon transit scintigraphy: analysis by colon activity profiles. 7 Nucl Med 1991;32:1668-74.

15 Kong MF, Perkins A, King P, et al. Reproducibility of gastric emptying of a pancake and milkshake meal in normal subjects. Nucl Med Comm 1998;19:77-82.

16 Lartigue S, Bizals Y, Des Varannes S, et al. Inter-and intrasubject variability of solid and liquid gastric emptying parameters. A scintigraphic study of healthy subjects and diabetic patients. Dig Dis Sci 1994;39:109-15.

17 Radloff LS. The CES-D scale: a self-report depression scale for research in the general population. Appl Psychol Measur 1977;1:385-401.

18 Spielberger CD, Gorsuch RL, Lushene R, et al. Manual for the state-trait anxiety inventory STAI (Form Y). Palo Alto, CA: Consulting Psych Press Inc., 1983.

19 Grayson D. A latent trait analysis of Eysenck Personality Questionnaire. f Psychiatr Res 1986;20:217-35.

20 Spielberger CD, Jacobs G, Russell S, et al. Assessment of anger: the State-Trait Anger Scale. In: Butcher JN, Spielberger CP, eds. Advances in personality assessment. Vol 2. Hillsdale, NY: LEA, 1983
21 Pilowsky I, Spence ND. Manual for the illness behaviour questionnaire (IBO) . 2nd ed. Adelaide, Australia: University of tionnaire $(I B Q)$.
Adelaide, 1983 .

22 Andrews $G$, Singh $M$, Bond $M$. The Defense Style Questionnaire. F Nerv Ment Dis 1993;181:246-56.

23 Watson M, Greer S. Development of a questionnaire measure of emotional control. F Psychosom Res 1983;27:299305.

24 Spielberger CD, Johnson EH, Jacobs GA, et al. The Anger for Behavioral Medicine and Community Psychology, Human Resources Institute, University of South Florida, Tampa, FL: 1987.

25 Boyd JH, Weissman MM, Thompson WD, et al. Screening for depression in a community sample. Arch Gen Psychiatry 1982;39:1195-200.

26 Youle MS, Read NW. Effect of painless rectal distension on gastrointestinal transit of solid meal. Dig Dis Sci 1984;29: $902-6$.

27 Lampe JW, Fredstrom S, Slavin J, et al. Sex differences in colonic function: a randomised trail. Gut 1993;34:531-6.

28 Probert CSJ, Emmett PM, Heaton KW. Intestinal transit time in the population calculated from self made observations of defecation. $\mathcal{F}$ Epidemiol Community Health 1993;47:331-3.

29 Wegener M, Borsch G, Schaffstein J, et al. Frequency of idiopathic gastric stasis and intestinal transit disorders in essential dyspepsia. F Clin Gastroenterol 1989;11:163-8.

30 Talley NJ, Shuter B, McCrudden G, et al. Lack of association between gastric emptying of solids and symptoms in nonulcer dyspepsia. F Clin Gastroenterol 1989; 11:625-30.

31 Cabellaro-Plasencia AM, Muros-Navarro MC, Martin-Ruiz J, et al. Dyspepsia symptoms and gastric emptying of solids in patients with functional dyspepsia. Role of Helicobacter pylori infection. Scand F Gastroenterol 1995;30:745-51.

32 Thompson WG, Creed F, Drossman DA, et al. Functional bowel disorders and functional abdominal pain. In: The functional gastrointestinal disorders diagnosis, pathophysiology,

33 Talley NJ. Diagnosing an irritable bowel: does sex matter? Gastroenterology 1991;100:834-7.

34 Gorard DA, Gomborone JE, Libby GW, et al. Intestinal transit in anxiety and depression. Gut 1996:39:551-5.

35 Wingate DL. Disorders of motility. In: DJ Weatherall, JG Ledingham, DA Warrell, eds. Oxford textbook of medicine. 2nd ed. Vol II. Section 12, 12.37-12.51. New York: Oxford University Press, 1987

36 Tucker DM, Sandstead H, Logan G, et al. Dietary fiber and personality factors as determinants of stool output. Gastroenterology 1981;81:879-83.

37 Smith RC, Greenbaum D, Vancouver J, et al. Psychosocial factors are associated with health care seeking rather than the bastroenterology 1990;98:293-301.

38 Drossman DA, McKee, DC, Sandler R, et al. Psychosocial factors in the irritable bowel syndrome: a multivariate study of patients and nonpatients with irritable bowel syndrome. Gastroenterology 1988;95:701-8.

39 Gomborone J, Dewsnap P, Libby G, et al. Abnormal illness attitudes in patients with irritable bowel syndrome. $\mathcal{f}$ Psychosom Res 1995;39:227-30. 